\title{
They ought to do it too: Understanding effects of social information on donation behavior and mood
}

\author{
Claire van Teunenbroek ${ }^{1}(1) \cdot$ René Bekkers $^{1}$ (i) $\cdot$ Bianca Beersma $^{2}$ (I)
}

Received: 8 June 2020 / Accepted: 8 December 2020 / Published online: 4 February 2021

(C) The Author(s) 2021

\begin{abstract}
Social information, providing potential donors with information about the donation amount given by earlier donors, is often applied as an intervention in online donation contexts. It has been suggested that social information informs others about the most common (descriptive norm) or appropriate (injunctive norm) behavior, and that these perceived social norms explain its effects. We present evidence from a preregistered online experiment testing to what extent perceived social norms mediate effects of social information on charitable giving. In addition, we examine whether social information affects donors' moods. A positive mood after donating is important to avoid negative side effects of a nudge like social information. We argue that social information increases social pressure to donate in a certain way and therefore decreases donors' moods. In an experiment among British citizens $(n=1029)$, we manipulated descriptive and injunctive social information. We show that injunctive social information, mentioning the appropriate donation amount, increases donation amounts (10\%) and donors' moods (10\%). Contrary to earlier research, merely stating descriptive social information did not affect the donation behavior or mood. We found no evidence that social information affects giving behavior or mood via perceived social norms. Our findings how different types of social information affect charitable giving are important for fundraisers or policy makers aiming to increase charitable behavior.
\end{abstract}

Keywords Donation behavior $\cdot$ Mood $\cdot$ Online experiment $\cdot$ Social information $\cdot$ Social norms

Claire van Teunenbroek

p.s.c.van.teunenbroek@vu.nl

René Bekkers

r.bekkers@vu.nl

Bianca Beersma

b.beersma@vu.nl

Extended author information available on the last page of the article 


\section{Introduction}

What happens when fundraisers mention the donation amount of other donors? An intervention often applied in online donation contexts is to provide social information, that is: to provide potential donors with information about the donation amount given by earlier donors. Influencing decision-making with a discrete suggestion, or "nudging" (see Thaler and Sunstein 2008), is increasingly popular. A nudge uses the human tendency to be influenced by ways in which information is presented and choices are constructed (Thaler and Sunstein 2008). Practitioners largely depend on the effect of social information to increase donations, especially now that donation amounts are decreasing (Bekkers and van Teunenbroek 2020; Van Teunenbroek and Bekkers 2020a). It is unclear, however, why social information affects charitable giving. A common explanation of the effects of social information refers to social information being perceived as a social norm. Even so, there are no studies that convincingly demonstrate that perceived social norms mediate social information effects in a charitable setting. Therefore, our central research question is: "To what extent does social information increase charitable giving and why?" With this research question, we aim to examine (1) a probable explanation for the direct effect of social information: social norms, and (2) a new outcome variable: mood.

First, we aim to test the proposed idea that social information effects are mediated by perceived social norms (Bicchieri and Xiao 2009; Croson et al. 2009; Goeschl et al. 2018; Van Teunenbroek and Bekkers 2020). In the literature on social norms, two categories of norms are usually distinguished: descriptive and injunctive social norms (Cialdini, Kallgren \& Reno, 1991). Descriptive norms reflect what is normally done in a certain situation: they give information about the prevalence of behavior. Injunctive norms reflect what most people consider the right thing to do: they give information about which behavior is appropriate. Croson et al. (2009) found that mentioning descriptive norms affects giving by affecting the perceived descriptive norm. Bicchieri and Xiao (2009) found that people do not distinguish between the two norms: social information in the form of a descriptive norm or in the form of an injunctive social norm both influenced the perceived descriptive and injunctive social norm (Bicchieri and Xiao 2009). We argue, however, that the findings of Bicchieri and Xiao (2009) may not directly translate to a charitable setting. The participants were asked to distribute an amount to another participant in a dictator game, which is more akin to private funding, while charities collect funding for a public good. Goeschl et al. (2018) did focus on a charitable context, but the participants were only presented with descriptive norms. In sum, these three experiments did include an explicit test for possible mediation of social information effects by perceived social norms, but the findings are either not directly applicable to a charitable context (Bicchieri and Xiao 2009), or ignored information based on injunctive norms (Croson et al. 2009; Goeschl et al. 2018). We will therefore further examine how social information changes charitable behavior by affecting the perception of social norms. In addition, we will test social information effects and measure perceived social norms in an online rather than an offline context. In an online context social pressure on adhering to norms is expected to be lower (Van Teunenbroek et al. 2020) and social information effects have been found to be less profound (Alpizar et al. 2008). As the importance of online fundraising for charities is increasing (Bekkers and van Teunenbroek 2020), it is 
important to examine whether social information and social norms exert similar effects on donation behavior as have been found in offline contexts.

Second, we examine whether social information affects not only donation behavior, but also people's mood. A common criticism of the use of social information and nudges in general is that it comes at a price: most people dislike being "nudged" because it reduces their perception of control (Hagmann, Reese, Seewalk \& Loeschinger, 2015; Brehm and Brehm 1981). People experience a positive mood when they feel in control of their own behavior (Dunn et al. 2014; Harbaugh et al. 2007). We argue that social information decreases feelings of control, by informing people how to behave in order to appear kind and generous. People care about attaining a positive perception of one's self (Bem 1972), and based on this, we expect people to follow the behavior of other kind and generous people to feel kind and generous as well. A potential donor might reason: 'I am a generous person, if other generous persons are donating a certain amount, I must do so as well'. In this way, social information could decrease the perception of control and therefore it could decrease peoples' mood. Thus, social information could lead to a long-term negative effect of social information on donating as it could lead to a negative view of, or even aversion against, donating. Should our results support this idea, this would be problematic for charities aiming to increase donations by providing potential donors with social information, as a positive mood is an important prerequisite for donating (O'Malley and Andrews 1983). A positive mood after donating, therefore, is important for retaining charitable behavior over time. Unfortunately, studies dedicated to social information effects have tended to focus exclusively on influencing donation behavior and have ignored donors' mood. This research seeks to fill this gap.

In the present study, we make a further attempt to clarify the effects of social information in a charitable context on people's decision to donate, the donation amount and their mood. We conducted a preregistered ${ }^{1}$ online experiment with British subjects accessed via an online platform (Prolific), in which we randomly assigned participants $(n=1029)$ to one of four conditions. In condition 1 , descriptive social information condition, we referred to the actual behavior of previous participants by mentioning: "Did you know that other participants gave £5?" In condition 2, injunctive social information condition, we referred to other participants' expected behavior by mentioning: "Did you know that other participants said that participants such as yourself should give $£ 5$ ? ” In condition 3, the both condition, we combined both social information types by mentioning both the expected and actual amounts: "Did you know that other participants gave $£ 5$ and they said that participants such as yourself should give $£ 5$ ?. In condition 4, the control condition, we did not provide participants with any social information.

\footnotetext{
${ }^{1}$ This manuscript was pre-registered as OTHERS ARE DOING IT TOO under number 20805 and available through AsPredicted at https://aspredicted.org/vz83y.pdf. Since the preregistration, we changed the order in which we discuss the hypotheses. An overview of the original lineup can be found in the electronic supplemental materials.
} 


\section{Prior research and hypotheses}

Most of the times people behave as others do (i.e. conforming, Bernheim 1994). Researchers have offered various reasons for why people conform. Psychologists describe that peoples' behavior is largely motived by social factors and avoiding social sanctions, such as a desire for acceptance, prestige and popularity (Bernheim 1994). However, in the absence of social monitoring and social sanctions, such as in an online environment, people have still been found to conform (Bøg et al. 2012; Raihani and Smith 2015; Sasaki 2019; Smith et al. 2015). For instance, Sasaki (2019) found that donors donating via an online platform in Japan prefer to donate amounts that resemble previously donated amounts. Thus, apparently, avoiding potential social sanctions is not the only reason why people conform. Maintaining a positive self-concept has also been argued to be an important motivator for following others (Brewer and Roccas 2001; Pool et al. 1998). Economists assume that people follow others because they are inclined to imitate those who are expected to be better informed (Bikhchandani et al. 1992; Conlisk 1980). Another explanation for following norms is that people act like others to create mutually positive externalities (Banerjee and Besley 1990; Katz and Shapiro 1986): if all donate higher amounts, the chance of reaching the target goal is higher.

From the above, it follows that if others' behavior is described, people tend to adjust their behavior to that of others (Van Teunenbroek et al. 2020). Studies show that, social information based on descriptive (for example, Kawamura, Ida \& Ogawa, 2019; Sasaki 2019; Van Teunenbroek and Bekkers 2020) or injunctive (Bicchieri and Xiao 2009) norms have been shown to increase donation amounts. Hence, both information about what others tend to do or what others see as appropriate should influence peoples' donation behavior. We examine how people adjust their donation amount as a function of the type of social norm that is tied to social information. We propose that:

\section{Hypothesis 1a: Descriptive social information increases the donation amount among donors.}

Hypothesis 1b: Injunctive social information increases the donation amount among donors.

The two types of norms do not always influence behavior to the same extent (Cialdini et al. 1991; Schultz et al. 2018). Bicchieri and Xiao (2009) found that participants in an offline dictator game are more likely to follow social information based on the descriptive than the injunctive norm, if both are present. The researchers explain their finding by observing that while people are expected to follow both type of norms, repercussions are less likely to occur when a large group is not following the norm. As a result, we expect that fewer people follow injunctive social information than descriptive social information. We examine whether this still holds in an online and charitable context, where the behavior is not observed by others. In doing so, we tested the following hypothesis:

Hypothesis 1c: Descriptive social information increases the donors' donation amount more than injunctive social information. 
Our next hypothesis refers to whether combining the descriptive and injunctive norm leads to a stronger effect than mentioning one at a time. We expect that social information based on both a descriptive and injunctive norm is more effective than information based on only one of these norms. More recent work on charitable behavior recognizes that a large percentage of donors donate while they prefer not to do so (that is, reluctant giving, DellaVigna et al. 2012; Andreoni et al. 2017). We argue that some people, presented with social information mentioning a descriptive norm, excuse themselves from following the information by telling themselves that they follow the injunctive norm instead, they might reason: "other donors might donate that amount but that does not mean that I have to do so." Alternatively, donors could ignore an injunctive social norm and follow the descriptive norm instead. In this case, someone might reason: "other people may think I ought to donate that amount, but other people are not doing it either." In both cases, donors come up with an excuse not to conform to the social norm and thus save money. However, if both norms are presented, no such excuses can be made, and it becomes harder to ignore the information. We examine if combining both norms leads to a stronger effect of social information; therefore, we tested the following hypothesis:

Hypothesis 1d: Mentioning both descriptive and injunctive social information increases the donation amount among donors more than mentioning either the descriptive or injunctive social information.

The prevailing suggestion for why people follow social information is because they interpret information about the behavior of others as a social norm (Blake et al. 1955; Bøg et al. 2012; Croson et al. 2009; Croson and Shang 2008, 2013; Edwards \& List, 2013; Meyer and Yang 2016; Murphy et al. 2015; Sasaki 2019; Smith et al. 2015). We are aware of three studies that included an explicit test of participants' perception of social norms (Bicchieri and Xiao 2009; Croson et al. 2009; Goeschl et al. 2018). These studies report that social information changes both the perceived descriptive norm (Bicchieri and Xiao 2009; Croson et al. 2009; Goeschl et al. 2018) and the injunctive norm (Bicchieri and Xiao 2009). Donors do not seem to distinguish between the actual or appropriate donation amount and are influenced by both forms of social information. In accordance, we propose that:

Hypothesis 2: The relation between social information and donation behavior is mediated by perceived social norms.

The few studies reporting social information effects on the decision to donate found no effect of social information on the participation rate (the decision to donate; Goeschl et al. 2018; Klinowski 2015; Murphy et al. 2015; Reingen 1982; Van Teunenbroek and Bekkers 2020). In the current study, participants were informed that they could make certain decisions with their windfall money (earned by winning a lottery after successfully completing a test), before being confronted with social information, namely in the introduction of the study. Because of this order, it is likely that some participants have already decided to keep the money instead of using it for something (like giving it away), before being confronted with social information. As a result, social information is unlikely to affect the decision to donate. In accordance, we propose that: 
Hypothesis 3: The decision to donate is similar among participants who received social information and participants who did not receive social information.

\subsection{Effects on mood}

Studies on prosocial behavior show that donors experience a positive mood change after donating, also referred to as the joy of giving (Steinberg 1987). A more recent study that randomly assigned participants to spend windfall money either on themselves or on someone else found that participants who gave away money reported happier moods (Dunn et al. 2020). It is suggested that people experience a positive mood after donating, because it alleviates feelings of guilt or it makes people feel better because they acted in line with a specific self-image (Bekkers and Wiepking 2011). In accordance we propose the following hypothesis ${ }^{2}$ :

\section{Hypothesis 4a: Donors report happier moods than non-donors.}

Yet the magnitude of the effect depends on the extent to which donors perceive autonomy with regard to the decision to donate or not (Dunn et al. 2014; Harbaugh et al. 2007); donors experience happier moods when they give more, rather than less, money away, but only if they have a choice about how much to donate (Weinstein and Ryan 2010). We argue that social information decreases feelings of autonomy, because it provides a possible answer to the question: how should I behave to be a kind and helpful person? According to self-perception theory, people want to retain a positive self-perception, which is attained by interpreting their own behavior (Bem 1972). Because social information shows the amount that other generous and kind people gave, it might make potential donors feel forced to follow the example set by social information, to feel kind and generous as well. As such, social information might decrease the perception of control: donating a certain amount (an amount that is in line with social information) confirms to the donor that she has positive personality traits (Baumeister 1998; Bem 1972), while deviating from the amount suggested by social information disconfirms this belief. Thus, donating an amount lower than the amount suggested by social information could make donors feel ungenerous and unkind, whereas an amount that is higher than the amount suggested by social information could make them feel like a show-off. What is left then, is to donate an amount that resembles the amount of others, which decreases donors perception of control and, as a result, their moods. Therefore, we expect that social information moderates the relation between donating and happiness. We propose the following hypothesis:

\footnotetext{
${ }^{2}$ Since the preregistration, we changed the presentation of this hypothesis ( $2 \mathrm{~d}$ in the preregistration), but the content remains the same. Hypothesis $2 \mathrm{~d}$ stated: "Individuals who donated feel happier than individuals who do not donate, but especially if they were not confronted with social information. Thus, social information moderates the relation between donating and happiness". We decided to split hypothesis $2 \mathrm{~d}$ into two separate hypotheses. First, we explain the direct effect of donating on mood (hypothesis 4a). Second, we discuss the moderating effect of social information (hypothesis $4 \mathrm{~b}$ ). We came to this decision after careful reflection, and we changed the presentation to make the text as simple as possible.
} 
Hypothesis 4b: The effect of donating on mood is moderated by social information, such that donors report happier moods than non-donors, especially if they were not presented with social information.

In addition, among those who decide to donate we expect a negative effect of social information on mood. As previously stated, people may experience decreasing control as a result of social information, which negatively affects donors' mood (Brehm and Brehm 1981) as human well-being partially depends on the feeling of autonomy (Weinstein and Ryan 2010). In accordance, we propose that (among donors only):

Hypothesis 4c: Descriptive social information decreases donors' moods.

Hypothesis 4d: Injunctive social information decreases donors' moods.

The existing research suggests that descriptive social norms affect behavior more strongly than injunctive social norms (Bicchieri and Xiao 2009; Rivis and Sheeran 2003). Therefore, we expect that descriptive social norms have a stronger negative effect on mood than injunctive social norms. To examine this, we propose the following hypothesis (among donors only):

Hypothesis 4e: Descriptive social information decreases donors' moods more so than injunctive social information.

We expect that presenting both forms of social information at the same time decreases the perception of control more than presenting just one form of social information. Freedom of choice is an important aspect of happiness (Weinstein and Ryan 2010), and we expect, therefore, that information based on both norms decreases the feeling of autonomy more than information based on one of these norms. In accordance, we propose that (among donors only):

Hypothesis 4f: Mentioning both descriptive and injunctive social information decreases donors' mood more than mentioning either the descriptive or injunctive social information.

In addition, we tested whether the relation between social information and mood is mediated by the perceived social norm, as suggested by the literature on social information effects on donation amounts (Bicchieri and Xiao 2009; Croson et al. 2009; Goeschl et al. 2018; Sasaki 2019; Smith et al. 2015; Van Teunenbroek and Bekkers 2020). Therefore, we tested the following hypothesis (among donors only):

Hypothesis 4g: The relation between social information and mood is mediated by perceived social norms.

\section{Methods}

To test the hypotheses, we conducted an online survey experiment on the British online platform Prolific, which enables researchers to find participants to collect reliable and 
high-quality data. The data for this study were collected between March 13, 2019 and March 19, 2019, resulting in a sample of 1029 participants. We invited only participants with British nationality for the experiment. No other requirements were set. The participants were paid per minute $(£ 8.58 / \mathrm{h}$.).

Before the data collection started, we conducted a power analysis to determine the required sample size at a .05 alpha and $80 \%$ power. We based the power on the minimal relevant effect size, which in our case is the effect of the injunctive social norm compared to the control condition. We expect the effect size to be small, an increase of $10 \%$. Based on a $10 \%$ effect size at a .05 alpha and $80 \%$ power we would need a sample of 787 . However, the $10 \%$ effect size is based on a sample consisting out of donors only. We expect a participation rate of $80 \%$, meaning that $20 \%$ is not expected to donate. If we include this in our calculation, we will need a sample of 984 participants. We preregistered the experiment and minimum sample size at Aspredicted.org (see https://aspredicted.org/vz83y.pdf).

\subsection{Participants}

The sample characteristics of the participants revealed that $64 \%$ of the participants identified themselves as women. The average age was 38 years $(S D=12.51)$. The largest share of participants donated to charities on a regular basis: $37 \%$ gave biannually, and $31 \%$ gave bi-monthly. Only $4 \%$ indicated that they gave rarely, and none of the participants indicated that they never donated on a yearly basis. Additional sample characteristics are outlined as electronic supplemental materials.

\subsection{Research design and procedure}

The study consisted of five parts: introduction, vocabulary test, donation task, survey and debriefing (see Fig. 1).

At the beginning of the study, we informed the participants that the study was part of a series of studies, and that this was a follow-up study. Participants were told that we might show them information about the behavior of participants in earlier studies, and that their own behavior and choices might be shown to other participants in later

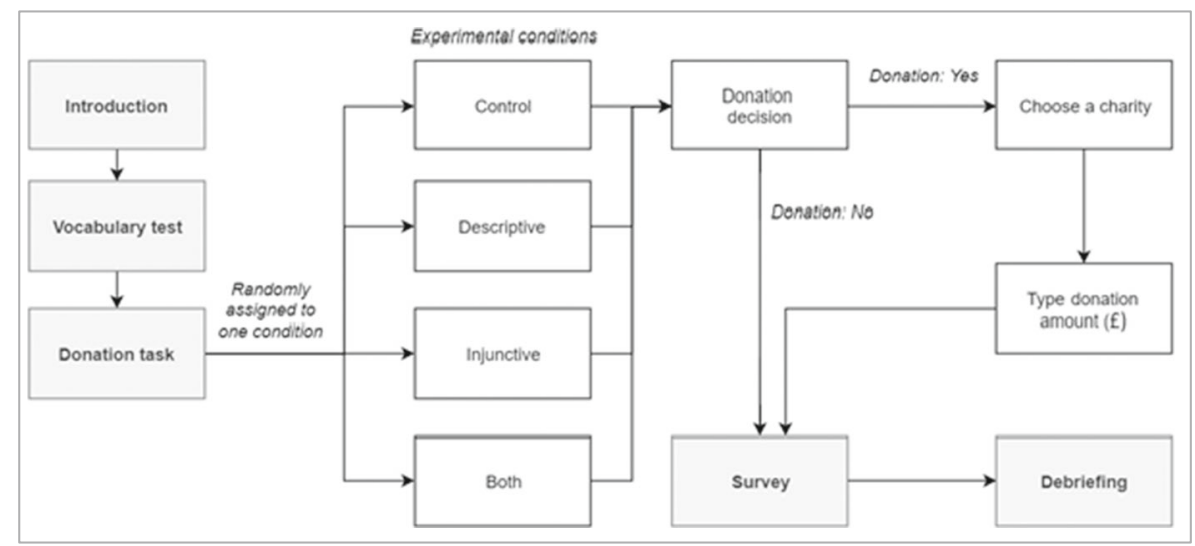

Fig. 1 Flowchart of the research design and procedure 
studies. In addition, we explained that we would raffle several $£ 10$ gift cards among those who successfully completed the vocabulary test and that they could decide what to do with the money.

We included the vocabulary test to make sure that if participants won the gift card, they felt they earned the $£ 10$. We used the vocabulary test from the General Social Survey in the United States (Malhotra et al. 2007). The test consists of ten items, ranging from very easy to difficult, which tests vocabulary knowledge. Each item includes a word for which participants must find the synonym out of a set of five choices. The score is calculated by adding the number of correct answers, with 10 being the highest possible score.

We did not clearly define a criterion for "success" in our study. Regardless of their performance, all participants were included in the lottery: we informed all participants that they had performed well enough to participate in the lottery, and all participants won a $£ 10$ gift card. After the lottery, participants entered the donation task (see the Supplementary Information for a full description), with which we assessed how people adjusted their donation behavior to social information as a function of the type of social norm tied to the information. We employed a 2 (social information based on a descriptive norm: yes vs. no) $\times 2$ (social information based on an injunctive norm: yes vs. no) design (see Table 1).

There was virtually no non-response (1\%), and a chi-square test confirmed that participants had been randomly assigned to one of the conditions $\left(X^{2}=4.23, n=1029\right.$, $p=.219$ ). After assigning participants to conditions, we presented them with a list of charities and measured the dependent variables "decision to donate" and "donation amount" by asking them if they wanted to keep the money, or if they wanted to donate a part of the $£ 10$ earnings to a charity of their choosing, and if so, how much.

The donation task was followed by a series of questions. To measure the dependent variable "mood", for instance, we asked participants one question, derived from Whillans et al. (2017): "How are you feeling at this moment?" Response options ranged from 1 ("Very bad") to 10 ("Very good"). To measure the mediator "perceived descriptive norms," participants were also asked to indicate how much they thought other people had donated (Goeschl et al. 2018): "On average, how much (of the 110 gift card) do you think other participants donated? Please indicate the amount". Participants could enter amounts ranging from $£ 0$ to $£ 10$. To measure the mediator "injunctive social norm", we asked participants to indicate how much they thought others should

Table 1 Schematic overview of the four conditions participants were randomly assigned to

\begin{tabular}{|c|c|c|c|}
\hline & & \multicolumn{2}{|l|}{ Descriptive social norm } \\
\hline & & No & Yes \\
\hline \multirow{2}{*}{$\begin{array}{l}\text { Injunctive } \\
\text { social } \\
\text { norm }\end{array}$} & No & Control: - & $\begin{array}{l}\text { Descriptive: Did you know that other } \\
\text { participants gave } £ 5 ?\end{array}$ \\
\hline & Yes & $\begin{array}{l}\text { Injunctive: Did you know that other } \\
\text { participants said that participants such } \\
\text { as yourself should give £5? }\end{array}$ & $\begin{array}{l}\text { Both: Did you know that other participants } \\
\text { gave £5 and said that participants such as } \\
\text { yourself should give £5? }\end{array}$ \\
\hline
\end{tabular}


have donated: "what amount do you think other participants should have donated?" Participants could enter amounts ranging from $£ 0$ to $£ 10$.

To verify that participants had perceived the manipulation, we asked them to describe the information in one or two sentences (in other words, social information manipulation check). The electronic supplementary information includes a full description of the manipulation check.

\subsection{Descriptive statistics and treatment of the data}

Table 2 shows the correlations between variables conducted among the complete sample (donors and non-donors). While we expected no effect of social information on the decision to donate, mentioning both norms correlated significantly with the decision to donate. Mentioning only descriptive or injunctive norms did not significantly correlate with the decision to donate. We expected a positive effect of social information on the donation amount, however, none of the conditions significantly correlated with the donation amount. We expected a negative effect of social information on donors' mood; however, we found a positive and significant correlation

Table 2 Intercorrelations between the main variables

\begin{tabular}{|c|c|c|c|c|c|c|c|c|c|}
\hline & 1 & 2 & 3 & 4 & 5 & 6 & 7 & 8 & 9 \\
\hline 1. Descriptive condition ${ }^{\mathrm{a}}$ & - & - & - & - & - & - & - & - & - \\
\hline 2. Injunctive condition ${ }^{\mathrm{a}}$ & $\begin{array}{l}-.33 * * * \\
(<.001)\end{array}$ & - & - & - & - & - & - & - & - \\
\hline 3. Both condition ${ }^{\mathrm{a}}$ & $\begin{array}{l}-.34 * * * \\
(<.001)\end{array}$ & $\begin{array}{l}-.34 * * * \\
(<.001)\end{array}$ & - & - & - & - & - & - & - \\
\hline 4. Donation decision ${ }^{\mathrm{b}}$ & $\begin{array}{l}-.04 \\
(.158)\end{array}$ & $\begin{array}{l}.01 \\
(.705)\end{array}$ & $\begin{array}{l}.06 \\
(.074)\end{array}$ & - & - & - & - & - & - \\
\hline 5. Donation amount ${ }^{\mathrm{c}}$ & $\begin{array}{l}-.04 \\
(.243)\end{array}$ & $\begin{array}{l}.02 \\
(.594)\end{array}$ & $\begin{array}{l}.04 \\
(.234)\end{array}$ & $\begin{array}{l}.79 * * * \\
(<.001)\end{array}$ & - & - & - & - & - \\
\hline 6. Mood ${ }^{\mathrm{d}}$ & $\begin{array}{l}-.001 \\
(.963)\end{array}$ & $\begin{array}{l}.07 * \\
(.033)\end{array}$ & $\begin{array}{l}-.001 \\
(.932)\end{array}$ & $\begin{array}{l}.13 * * * \\
(<.001)\end{array}$ & $\begin{array}{l}.14 * * * \\
(<.001)\end{array}$ & - & - & - & - \\
\hline 7. Perceived descriptive norm ${ }^{\mathrm{e}}$ & $\begin{array}{l}-.07 * \\
(.032)\end{array}$ & $\begin{array}{l}-.004 \\
(.900)\end{array}$ & $\begin{array}{l}-.004 \\
(.895)\end{array}$ & $\begin{array}{l}.08^{* *} \\
(.009)\end{array}$ & $\begin{array}{l}.30 * * * \\
(<.001)\end{array}$ & $\begin{array}{l}.03 \\
(.430)\end{array}$ & - & - & - \\
\hline 8. Perceived injunctive norm ${ }^{\mathrm{e}}$ & $\begin{array}{l}-.05 \\
(.126)\end{array}$ & $\begin{array}{l}.003 \\
(.936)\end{array}$ & $\begin{array}{l}-.01 \\
(.770)\end{array}$ & $\begin{array}{l}.36 * * * \\
(<.001)\end{array}$ & $\begin{array}{l}.55 * * * \\
(<.001)\end{array}$ & $\begin{array}{l}.09 * * \\
(.005)\end{array}$ & $\begin{array}{l}.52 * * * \\
(<.001)\end{array}$ & - & - \\
\hline 9. Manipulation check $^{\mathrm{f}}$ & $\begin{array}{l}.26 * * * \\
(<.001)\end{array}$ & $\begin{array}{l}.09^{* *} \\
(.003)\end{array}$ & $\begin{array}{l}.25 * * * \\
(<.001)\end{array}$ & $\begin{array}{l}.15 \\
(.621)\end{array}$ & $\begin{array}{l}-.09 * \\
(.004)\end{array}$ & $\begin{array}{l}-.02 \\
(.551)\end{array}$ & $\begin{array}{l}-.15 * * * \\
(<.001)\end{array}$ & $\begin{array}{l}-.003 \\
(.915)\end{array}$ & - \\
\hline
\end{tabular}

$N=1029$, including both donors and non-donors. The $p$-values are reported between the brackets

${ }^{a}$ The different social information conditions are included as dummies on a set of $0-1$ indicators for each condition, with participants of the control group in the (omitted) reference category

b $1=$ if a participant decided to donate and $0=$ if a participant decided not to donate (i.e. non-donors)

c Values reflect the donation amount, answers ranged from 0 to 10

dValues reflect a participants' mood on a scale from 0 to 10

e Values reflect the perceived norm, answers ranged from 0 to 10

f $1=$ saw the manipulation and $0=\operatorname{did}$ not see the manipulation

$* * *$ indicates $p<.001, * *$ indicates $p<.01$, * indicates $p<.05$ 
between the injunctive condition and mood. Mentioning descriptive or both norms correlated negatively with donors' mood, but not significantly so.

The perceived descriptive and injunctive norms correlated significantly with both the decision to donate and the donation amount, with the perceived injunctive norm resulting in a stronger correlation. However, donors' mood was only significantly correlated with the perceived injunctive norm, and not with the perceived descriptive norm. The two perceived norms were significantly and positively correlated. In addition, there was no significant correlation between our manipulation and the perceived social norms. An exception is the negative correlation between the descriptive condition and the perceived descriptive norm. It appears that the descriptive condition is correlated with a lower perceived descriptive norm, while we expected this relationship to be positive. Overall, we conclude that our manipulation barely or not at all affected the perceived norms.

The histograms in Fig. 2 show a peak of $£ 10$ donations at the far end. The peak occurs in all four conditions, suggesting that social information had no effect on the number of donors giving $£ 10$ : the percentage of participants donating $£ 10$ was similar across different conditions (see Table 3 ).

While the social norm provided them with an excuse to give $£ 5$ and save money (Van Teunenbroek and Bekkers 2020), this group of participants still gave away their complete endowment. Deaton and Cartwright (2018) suggest that eliminating observations is appropriate in some cases. As we know that social information effects are restricted (in other words, not everyone is affected, see Murphy et al. (2015) and Shang et al. (2009)), and as earlier studies report that a minority of participants in giving experiments donate their complete endowment regardless of the treatment they receive (Bekkers 2012, 2015; Engel 2011; Thöni and Volk 2018), we excluded the group of

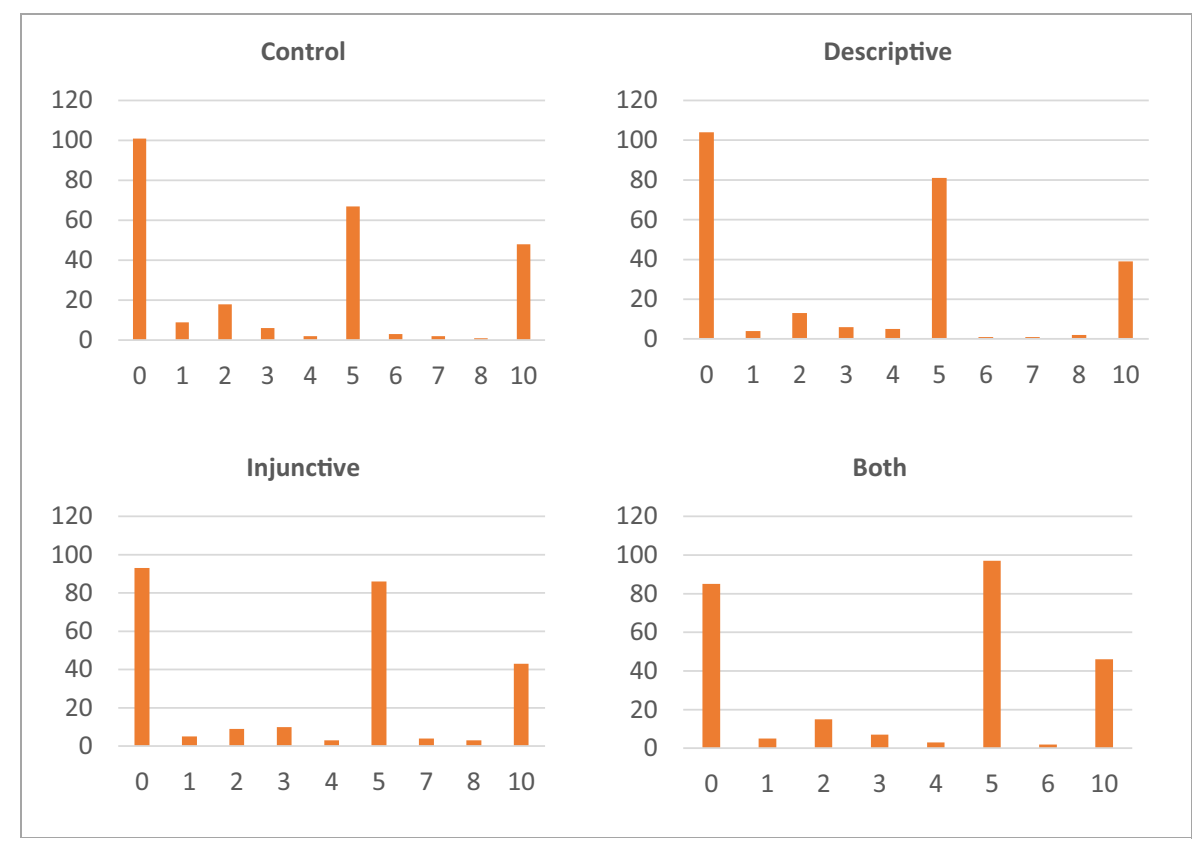

Fig. 2 Histograms reporting the frequencies of the amounts donated by condition 
Table 3 Distribution of donation amounts by conditions

\begin{tabular}{|c|c|c|c|c|c|}
\hline & \multirow{2}{*}{$\begin{array}{l}\text { All participants } \\
£ 0\end{array}$} & \multicolumn{4}{|c|}{ Among donors } \\
\hline & & $£ 1-£ 5^{*}$ & $£ 5 * *$ & $£ 6-£ 9$ & $£ 10$ \\
\hline Control & $61 \%$ & $53 \%$ & $26 \%$ & $2 \%$ & $19 \%$ \\
\hline Descriptive condition & $59 \%$ & $52 \%$ & $32 \%$ & $2 \%$ & $15 \%$ \\
\hline Injunctive condition & $64 \%$ & $47 \%$ & $34 \%$ & $3 \%$ & $17 \%$ \\
\hline Both condition & $68 \%$ & $44 \%$ & $37 \%$ & $1 \%$ & $18 \%$ \\
\hline Total & $63 \%$ & $49 \%$ & $32 \%$ & $2 \%$ & $17 \%$ \\
\hline
\end{tabular}

** significant at a .01 level, * significant at a .05 level

donors who donated $£ 10(n=176)$ from our analysis. The findings including all donors can be found as electronic supplemental materials.

Apart from Hypotheses 3, 4a and 4b, we tested the hypotheses among donors only. We opted for this method to make the results comparable with the leading articles focused on social information effects in a charitable context (Croson et al. 2009; Croson and Shang 2008, 2013; Shang and Croson 2009; Shang, Reed \& Croson 2008), since these analyzed effects solely among donors.

\section{Results}

Table 4 reports the descriptive statistics by condition. We will discuss the hypotheses one by one in the sections below. Unless noted otherwise, we conducted a multiple regression analysis in which we regressed the donation amount on a set of 0-1 indicators for each condition, with participants of the control group in the (omitted) reference category.

Table 4 Descriptive statistics by condition, with the control group as a reference

\begin{tabular}{|c|c|c|c|c|c|c|}
\hline & $\begin{array}{l}\text { Number of } \\
\text { participants }\end{array}$ & $\begin{array}{l}\% \text { that } \\
\text { gave }\end{array}$ & $\begin{array}{l}\text { Average } \\
\text { donation } \\
\text { amount }^{\mathrm{a}}\end{array}$ & $\begin{array}{l}\text { Average } \\
\text { donors' } \\
\text { mood }^{\mathrm{a}}\end{array}$ & $\begin{array}{l}\text { Perceived } \\
\text { descriptive } \\
\text { norm }^{\mathrm{a}}\end{array}$ & $\begin{array}{l}\text { Perceived } \\
\text { injunctive } \\
\text { norm }^{\mathrm{a}}\end{array}$ \\
\hline Control condition & 209 & $52 \%$ & $\begin{array}{l}4.10 \\
(S D=1.62)\end{array}$ & $\begin{array}{l}6.39 \\
(S D=1.87)\end{array}$ & $\begin{array}{l}4.06 \\
(S D=1.86)\end{array}$ & $\begin{array}{l}4.23 \\
(S D=1.98)\end{array}$ \\
\hline $\begin{array}{l}\text { Descriptive } \\
\text { condition }\end{array}$ & 217 & $52 \%$ & $\begin{array}{l}4.45^{(*)} \\
(S D=1.31)\end{array}$ & $\begin{array}{l}6.73 \\
(S D=1.78)\end{array}$ & $\begin{array}{l}4.20 \\
(S D=1.38)\end{array}$ & $\begin{array}{l}4.59 \\
(S D=1.74)\end{array}$ \\
\hline $\begin{array}{l}\text { Injunctive } \\
\text { condition }\end{array}$ & 213 & $57 \%$ & $\begin{array}{l}4.53^{*} \\
(S D=1.43)\end{array}$ & $\begin{array}{l}7.02^{*} \\
(S D=2.03)\end{array}$ & $\begin{array}{l}4.35 \\
(S D=1.32)\end{array}$ & $\begin{array}{l}4.64 \\
(S D=1.83)\end{array}$ \\
\hline Both & 214 & $61 \%$ & $\begin{array}{l}4.35 \\
(S D=1.28)\end{array}$ & $\begin{array}{l}6.78 \\
(S D=1.85)\end{array}$ & $\begin{array}{l}4.22 \\
(S D=1.22)\end{array}$ & $\begin{array}{l}4.43 \\
(S D=1.80)\end{array}$ \\
\hline All & 853 & $56 \%$ & $\begin{array}{l}4.36 \\
(S D=1.42)\end{array}$ & $\begin{array}{l}6.78 \\
(S D=1.85)\end{array}$ & $\begin{array}{l}4.21 \\
(S D=1.45)\end{array}$ & $\begin{array}{l}4.48 \\
(S D=1.84)\end{array}$ \\
\hline
\end{tabular}

a Among donors only

* significant at a .05 level, ${ }^{*}$ ) significant at a .10 level 


\subsection{Social information increased donation amounts}

We hypothesized a positive effect of all three forms of social information (Hypotheses 1a, $1 \mathrm{~b}$ and 1d). Our data only support Hypothesis 1b, with a positive effect of social information using an injunctive norm. Participants who were informed about injunctive social information gave $10 \%$ higher amounts $(M=4.53, S D=1.43)$ than participants who received no social information $(M=4.10, S D=1.62), b=.43, n=473 p=.022$.

We found no support for Hypothesis 1a, in which we predicted a positive effect of social information using a descriptive social norm. While participants presented with descriptive social information donated 9\% higher amounts than participants who received no social information, the difference was only marginally significant ( $b=.35, n=473 p=.065)$. In addition, we found no support for Hypothesis $1 \mathrm{~d}$, in which we expected that presenting both norms would affect donation amounts. Participants confronted with both types of social information at the same time donated $6 \%$ higher amounts than those who received no social information, but the difference was not significant $(b=.25, n=473, p=.168)$.

In addition, we found no support for Hypothesis 1c, stating that descriptive norms would increase the donation amounts more so than injunctive norms. We conducted a multiple regression analysis in which we regressed the donation amount on a set of $0-1$ indicators for each condition, with participants of the injunctive group in the (omitted) reference category. Compared with injunctive social information, descriptive social information yielded similar donation amounts. The difference between the descriptive and injunctive condition was not significant (see Table 5).

\subsection{Social information effects on donation amounts are not mediated by perceived social norms}

We hypothesized (H2) that the effect of social information on donation amounts among donors would be mediated by the perception of social norms. To test the mediations with the multicategorical independent variable (i.e. different forms of social information), we used the PROCESS model for multicategorical independent variable of Hayes and Preacher (2014). We used indicator coding (i.e. dummy coding), where the control group functions as the reference group. Using dummy coding for the independent

Table 5 Multiple regression with dummies for social information on donation amounts, with the injunctive group in the reference category $(n=473)$

95\% Confidence interval

\begin{tabular}{llllr} 
& $b(S E)$ & $p$-value & Lower bound & Upper bound \\
\hline Constant & $4.53(.13)$ & .001 & 4.277 & 4.781 \\
Descriptive condition & $-.08(.19)$ & .674 & -.440 & .285 \\
Both condition & $-.18(.18)$ & .326 & -.525 & .175 \\
Control condition * & $-.43(.19)$ & .022 & -.794 & -.062 \\
\hline
\end{tabular}

* significant at a .05 level 
variable, the mediation model is parameterized with two equations, one for the mediator $(M)$ and one for the dependent variable $(Y)$ :

$$
\begin{gathered}
M=i_{1}+\mathrm{a}_{1} D_{1}+\mathrm{a}_{2} D_{2}+\mathrm{a}_{3} D_{3}+e_{M} \\
Y=i_{2}+c_{1}^{\prime} D_{1}+c_{2}^{\prime} D_{2}+c_{3}^{\prime} D_{3}+e_{y}
\end{gathered}
$$

This approach ensures that we retain all information about how the three treatment groups differ from the control group. The total effect $\left(c_{i}\right)$ and relative direct effect $\left(c^{\prime}{ }_{i}\right)$ are reported in Fig. 3. The relative indirect effect $\left(a_{i} b_{i}\right)$ in this model refers to the effect of social information on donation amount through perceived social norms. First, we discuss the relative indirect effect through the perceived descriptive norm, and second, we discuss the effect through the injunctive norm. There was no significant relative indirect effect of mentioning descriptive social information on donation amounts through perceived descriptive norms, $b=.05$, BCa CI $[-0.731,0.263]$. There was no significant indirect effect of mentioning injunctive social information on donation amounts through perceived descriptive norms, $b=.11$, BCa CI $[-0.055,0.255]$. There was no significant relative indirect effect of mentioning both types of social information on donation amounts through perceived descriptive norms, $b=.06$, BCa CI [-0.055, 0.255].

We found similar effects with the perceived injunctive norm, namely no significant relative indirect effect of either of the social information forms on donation amounts. There was no significant relative indirect effect of mentioning descriptive social information on donation amounts through perceived injunctive norms, $b=.001, \mathrm{BCa}$ CI $[-0.032,0.201]$. There was no significant indirect effect of mentioning injunctive social information on donation amounts through perceived injunctive norms, $b=.001$,

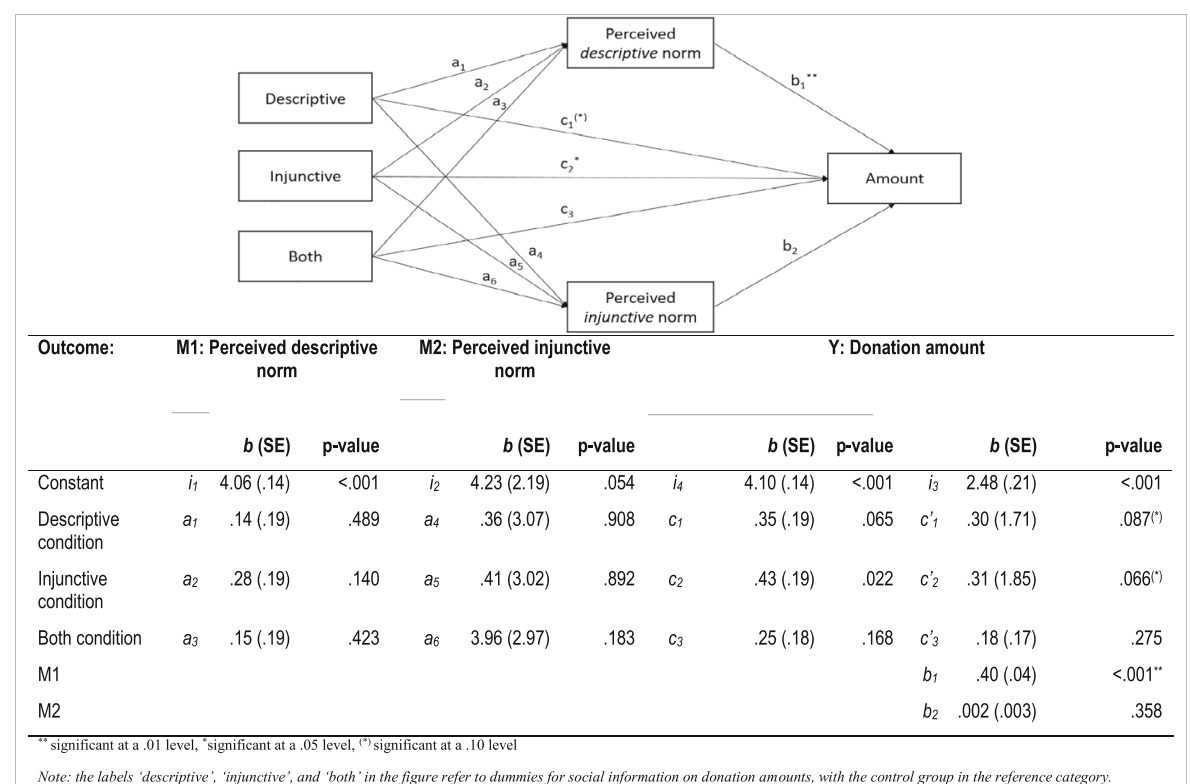

Fig. 3 Model of social information (included as dummies) as a predictor of donation amounts, mediated by two mediators in parallel: relation perceived descriptive injunctive social norm 
BCa CI $[-0.013,0.255]$. There was no significant relative indirect effect of mentioning both types of information on donation amounts through perceived injunctive norms, $b=.01, \mathrm{BCa}$ CI $[-0.140,0.074]$.

In sum, the perceived norms were unaffected by our manipulation of mentioning social information. However, the perceived descriptive norm was correlated with the donation amount, while the perceived injunctive norms were not correlated with the donation amount. The analysis does not support Hypothesis 2, the relation between social information and donation behavior is not mediated by perceived social norms.

\subsection{No increase in the decision to donate because of social information}

We expected no effect of social information on the decision to donate, see Hypothesis 3 , to test this we run a series of chi square tests. As expected, none of the conditions significantly increased the number of donors (see Table 4), in comparison with the control group. A chi-square test shows that stating descriptive social information left the number of donors unaffected, $\left.X^{2}(1, N=426)<.01, p=.987\right)$. Stating injunctive social information increased the proportion of participants making donations but this difference was not significant $\left(X^{2}(1, N=422)=.92, p=.337\right)$. Stating both norms seems to increase the proportion of donors more strongly, but the difference was not significant at conventional levels $\left(X^{2}(1, N=423)=3.18, p=.075\right)$. The results support Hypothesis 3; social information did not affect the decision to donate.

\subsection{Donating increases participants' mood}

In Hypothesis 4a, we predicted a positive effect of the decision to donate on mood. As expected, a regression analysis showed that donors reported $9 \%$ happier moods $(M=$ $6.74, S D=1.89)$ than non-donors $(M=6.17, S D=2.22), b=.57, n=853, p<.001$. We found no support for Hypothesis $4 \mathrm{a}$.

In Hypothesis 4b, we predicted that the positive effect of the decision to donate on mood would be stronger among participants presented with social information. To review whether the relation of the decision to donate on mood was moderated by any of the social information conditions, we used the PROCESS model for multicategorical moderating variable. We regressed the effect of donating on peoples' mood, including social information as a moderator on a set of $0-1$ indicators for each condition, with participants of the control group in the (omitted) reference category.

None of the social information conditions moderated the effect of donating on peoples' mood (see Table 6). We found no support for Hypothesis $4 \mathrm{~b}$.

\subsection{Social information increases donors' mood}

Next, we tested how donors' moods were affected by social information. We hypothesized a negative effect of all three forms of social information on the donors' mood (Hypotheses 4c, 4d and 4f). However, we found a positive direction for all forms of social information, though not all significant (see Table 4). We found effects like those found for donation amount: solely mentioning injunctive social information resulted in a significant positive effect. Though we expected a negative effect, donors informed about injunctive social information reported significantly better moods (10\%) than 
Table 6 Multiple regression with donors as a predictor of peoples' mood, and social information as a moderator. With dummies for social information, with the control group in the reference category $(n=853)$

\begin{tabular}{lcccc}
\hline & & & \multicolumn{2}{l}{$95 \%$ Confidence interval } \\
\cline { 4 - 5 } & $\mathrm{b}(\mathrm{SE})$ & $p$-value & Lower bound & Upper bound \\
\hline Constant & $6.11(.20)$ & $<.001$ & 5.709 & 6.511 \\
Donation decision & $.28(.28)$ & .331 & -.280 & .831 \\
Descriptive condition & $.01(.29)$ & .985 & -.556 & .567 \\
Injunctive condition & $.28(.30)$ & .344 & -.298 & .861 \\
Both condition & $-.04(.30)$ & .899 & -.632 & .555 \\
Descriptive condition *donation decision & $.34(.40)$ & .399 & -.443 & 1.113 \\
Injunctive condition *donation decision & $.36(.40)$ & .371 & -.427 & 1.143 \\
Both condition *donation decision & $.43(.40)$ & .285 & -.340 & 1.220 \\
\hline
\end{tabular}

** significant at a .01 level, ${ }^{*}$ significant at a .05 level, ${ }^{(*)}$ significant at a .10 level

participants in the control condition $(b=.64, n=473, p=.011)$. The size of the effect of injunctive social information on donors' moods (10\%) is in line with the effects on the donation amount (also about $10 \%$ ).

Mentioning descriptive social information had no effect on donors' moods (Hypothesis $4 \mathrm{c}$ ). While a regression analysis showed that participants confronted with descriptive social information reported higher levels of happiness $(5 \%)$ than participants who received no social information, the effect was not significant $(b=.34, n=473$, $p=.179$ ). In addition, mentioning both social information types at the same time did not significantly affect donors' moods (Hypothesis 4f). While donors confronted with both types of social information reported $6 \%$ better moods than those who received no social information, the effect was not significant, $b=.39, n=473, p=.110$.

We found no support for Hypothesis 4e, stating that descriptive social information had a stronger negative effect than injunctive social information. We conducted a multiple regression analysis in which we regressed the donors' mood on a set of $0-1$ indicators for each condition, with participants of the injunctive group in the (omitted) reference category. Compared with injunctive social information, the descriptive social information decreased donors' mood with $4 \%$. The difference between the injunctive and descriptive condition was not significant (see Table 7), $b=-.30, n=473, p=.226$.

Table 7 Multiple regression with dummies for social information effects on donors' mood, with the injunctive group in the reference category $(n=473)$

$95 \%$ Confidence interval

\begin{tabular}{|c|c|c|c|c|}
\hline & \multirow[b]{2}{*}{$b(S E)$} & \multirow[b]{2}{*}{$p$ value } & \\
\hline & & & Lower bound & Upper bound \\
\hline Constant & $7.03(.17)$ & $<.001$ & 6.688 & 7.362 \\
\hline Descriptive condition & $-.30(.25)$ & .226 & -.784 & .186 \\
\hline Both condition & $-.25(.24)$ & .299 & -.716 & .220 \\
\hline Control condition* & $-.64(.25)$ & .011 & -1.129 & -.150 \\
\hline
\end{tabular}

** significant at a .01 level, ${ }^{*}$ significant at a .05 level, ${ }^{(*)}$ significant at a .10 level 
In addition, we examined whether the effect of social information on donors' mood was mediated by their donation amount. We once again relied on the PROCESS model for multicategorical independent variable of Hayes and Preacher (2014): conducting a mediation analyses with dummy coding for the independent variable, with participants of the control group in the (omitted) reference category. The total effect $\left(\mathrm{c}_{\mathrm{i}}\right)$ and relative direct effect $\left(\mathrm{c}_{\mathrm{i}}\right)$ are reported in Fig. 4.

The relative indirect effect $\left(a_{i} b_{i}\right)$ in this model refers to the effect of social information on donors' mood through donation amounts. There was a significant relative indirect effect of mentioning the injunctive norm on donors' mood through donation amounts, $b=.09$, BCa CI [0.010, 0.220]. Hayes and Preacher (2014) discourage reporting an effect size while working with relative effect sizes, since contrast options are not yet available for mediations with multicategorical independent variables.

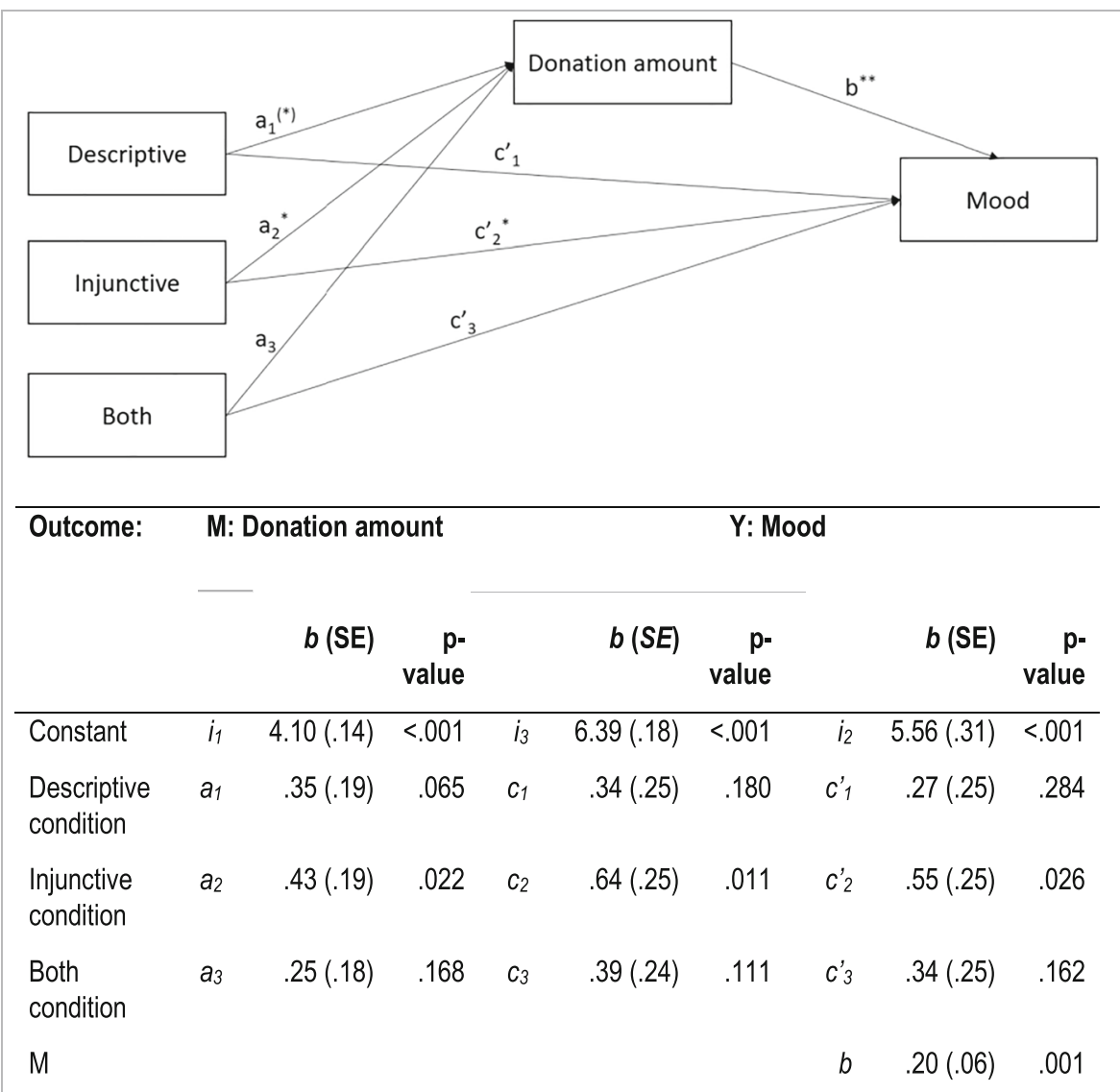

${ }^{* *}$ significant at a .01 level, ${ }^{*}$ significant at a .05 level, ${ }^{(*)}$ significant at a .10 level

Note: the labels 'descriptive', 'injunctive', and 'both' in the figure refer to dummies for social information on donation amounts, with the control group in the reference category.

Fig. 4 Model of social information (included as dummies) as a predictor of donors' mood, mediated by donation amount 
However, we do see that including donation amount as a mediator decreases the correlation between injunctive norm and mood with only $14 \%$. Therefore, the effect of injunctive norms on mood is unlikely to be fully mediated by donation amounts. There was no significant relative indirect effect of mentioning the descriptive norm, $b=.09$, BCa CI $[-0.001,0.204]$. Nor was there a significant relative indirect effect of mentioning the both norms, $b=.05$, BCa CI $[-0.015,0.163]$.

In sum, the effect of mentioning injunctive norms on donors' mood is mediated by the donation amount, but the effects of mentioning descriptive or both norms are not. Mentioning the injunctive norm increases participants donation amounts and as a result', their mood.

\subsection{Social information effects on donors' mood are not mediated by perceived social norms}

As a final step, we tested whether the effect of social information on donation amounts was mediated by perceived norms (Hypothesis 4g). Like the effect on the donation amount, however, the relation between social information and mood was not mediated by perceived social norms. We used the PROCESS model for multicategorical independent variable of Hayes and Preacher (2014), with participants of the control group in the (omitted) reference category. The total effect $\left(c_{i}\right)$ and relative direct effect $\left(c^{\prime}{ }_{i}\right)$ are reported in Fig. 5. The relative indirect effect $\left(\mathrm{a}_{\mathrm{i}} \mathrm{b}_{\mathrm{i}}\right)$ in this model is the effect of social information on donors' mood through perceived social norms. Which was constructed by multiplying $a_{i}$ by $b_{i}$. First, we discuss the relative indirect effect through the perceived descriptive norm, and second, we discuss the effect through the injunctive norm.

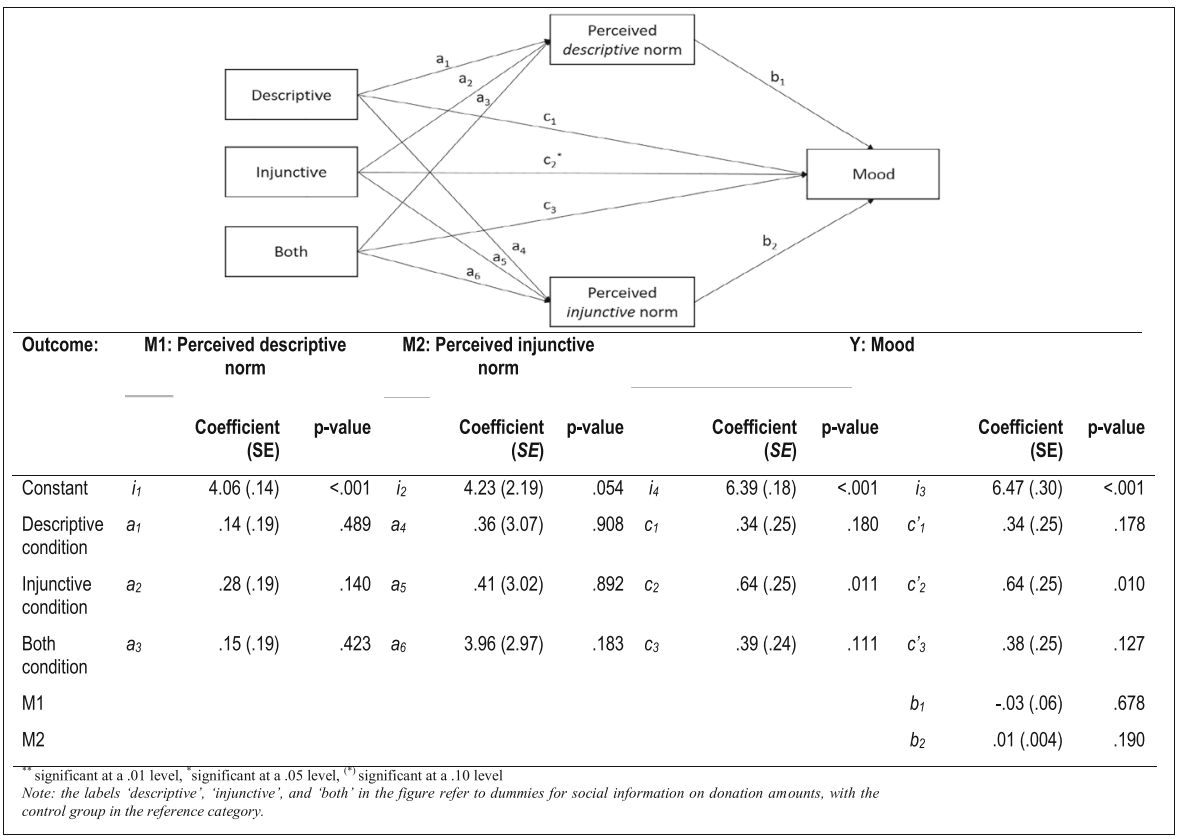

Fig. 5 Model of social information (included as dummies) as a predictor of donors' mood, mediated by two mediators in parallel: relation perceived descriptive injunctive social norm 
There was no significant relative indirect effect of mentioning descriptive social information on peoples' mood through perceived descriptive norms, $b=-.003$, BCa CI [ $-0.067,0.022]$. There was no significant indirect effect of mentioning injunctive social information on donation amounts through perceived descriptive norms, $b=-.01$, BCa CI $[-0.075,0.031]$. There was no significant relative indirect effect of mentioning both types of information on donation amounts through perceived descriptive norms, $b=-.004$, BCa CI [ $-0.001,0.002]$.

We found similar effects with the perceived injunctive norm, namely no significant indirect effect of either of the social information forms on peoples' mood. There was no significant relative indirect effect of mentioning descriptive social information on peoples' mood through perceived injunctive norms, $b=.002$, BCa CI $[-0.014,0$. 055]. There was no significant relative indirect effect of mentioning injunctive social information on peoples' mood through perceived injunctive norms, $b=.002$, BCa CI $[-0.032,0.058]$. There was no significant relative indirect effect of mentioning both types of information on peoples' mood through perceived injunctive norms, $b=.02$, $\mathrm{BCa}$ CI $[-0.032,0.058]$. Our data does not support Hypothesis $4 \mathrm{~g}$, the relation between social information and donors' mood is not mediated by perceived social norms.

\section{Discussion and conclusion}

This study set out to investigate the effects of social information on donation behavior and mood. Our online experiment among British citizens reveals a series of results with important implications for both theory and various actors in practice. First, we found that the decision to donate was positively affected by social information, but not significantly so. The strength of the effect depends on the social information mentioned. Mentioning both the descriptive and injunctive social information at the same time resulted in the highest participation rate (16\%), but the effect was only marginally significant. Mentioning only the descriptive social information did not affect the decision to donate $(0 \%)$, which is in line with earlier studies (Goeschl et al. 2018; Klinowski 2015; Murphy et al. 2015; Reingen 1982). Mentioning injunctive social information increased the participation rate with $9 \%$, but not significantly so.

Second, a small difference emerged between the conditions in terms of the donation amount, indicating that donors gave slightly higher amounts when social information was provided. However, only mentioning injunctive social information resulted in a significant effect, increasing donations with $10 \%$. Please note that the effect is small and that we needed the increased power of a larger sample to detect the effect. However, we do not perceive our sample as too big to fail (i.e. even miniscule effects can become statistically significant if the sample is too big, see Lin et al. (2013)), since the larger effect size $(16 \%)$ on the number of donors in the both condition was not significant. The small effect size of $10 \%$ resembles effect sizes found in earlier studies (Bekkers 2012; Croson and Shang 2008; Shang et al., 2012; Shang and Croson 2009; Van Teunenbroek 2016). These earlier studies, however, mostly focused on providing social information based on descriptive social norms, except for Bicchieri and Xiao (2009), who also reported a positive effect of injunctive norms. Hence, our study provides one of the first indications of social information effects reporting injunctive social norms.

Contrary to most literature reporting on social information effects, mentioning descriptive social information did not significantly increase donation amounts but 
resulted in a non-significant increase of $9 \%$, compared to the control condition. However, our study is not the first to report no effect, see Catt and Benson 1977; Kubo et al. 2018; Murphy et al. 2015 and Shang and Croson 2009. It is possible that the online context in which we conducted our study influenced the effect of social information (see also Van Teunenbroek et al. 2020). Earlier we discussed that a reason why people tend to follow descriptive social norms is that these norms give them the idea that a large group of people is engaging in the same behavior and that deviating from this norm might be punished. The online nature of our experiment caused social control and therefore social sanctions to play a less important role, since participants made their choices without being observed by others. This may have caused social information based on descriptive norms to be less influential in this context. Injunctive norms, on the other hand, are applicable in multiple settings and convey more general rules about what sort of behavior is appropriate (Reno et al., 1993).

Confronting participants with both information types at the same time resulted in a higher participation rate (while not significantly so). In addition, it did not increase donation amounts, but resulted in a non-significant increase of $6 \%$, compared to the control condition. If we observe the donation amounts more closely, we see that the both condition includes the highest percentage of donors donating low amounts and the lowest percentage of donors donating amounts above the suggestion of five pounds. The combination of these findings could explain why the injunctive condition does result in an increase in the average donation amount, while the both condition does not. The findings suggest that social information in the form of both social information types increased the number of donors, but also increased the number of low donations (something that has been referred to as "reluctant giving" In earlier studies, see for example: DellaVigna et al. 2012; Andreoni et al. 2017).

Third, in contrast to the predicted negative effect, we found a positive effect of social information on mood. Only mentioning injunctive social information resulted in a significant effect on mood (in other words, it led to a $10 \%$ increase in mood compared to the control condition). This effect size was similar in size as the effect on the donation amount. Our results are the first to report on social information effects on donors' moods. We expected a negative effect of social information on donors' moods, based on the earlier finding that a decreasing perception of control negatively affects donors' moods (Brehm and Brehm 1981) and we expected social information to result in such a decreased perception of control. However, our results suggest that social information does not lead to a decreasing perception of control because a positive perception of control is associated with a positive mood effect (Brehm \& Brem, 1981). Donors apparently perceived freedom of choice, regardless of being confronted with social information. In the absence of a decreased perception of control, our finding of a positive mood effect is in line with the finding that donors experience happier moods when they give more, rather than less money away (Weinstein and Ryan 2010). Thus, the positive mood effect is likely the result of donors donating higher amounts, which is confirmed by our mediation analyses that show that the effect of social information on donors' moods was mediated by the donation amount. This might also explain why the effect of mentioning descriptive or both social information types on donors' moods is not significant; donors were not stimulated to donate high enough amounts to experience a positive mood change. We analyzed the effect of social information on mood among donors only. The effect we obtained may be an underestimation, since donors reported happier moods than non-donors. 
Fourth, we found no mediation effect of perceived social norms on the relation between social information and the donation amount or mood. While perceived social norms affect donation amounts, our manipulation did not affect the perceived social norms. The absence of such a mediation could be context-related: social norms have a more profound impact in a context where there is direct contact between participants, and the context of our study did not allow for any contact between the participants. Another explanation is the order in which we measured the dependent and mediating variables. Since we measured the perceived norms after participants indicated their decision (Bekkers 2012; Bicchieri and Xiao 2009), participants may have adapted their perceptions of norms after they engaged in charitable giving (Bekkers 2012). Bekkers found that the donation amounts were consistent with the perceived norm, but only if participants indicated the perceived social norm after donating.

Fifth, in line with earlier findings (see Murphy et al. 2015 and Shang et al., 2009), our results identify a group of donors that is unaffected by social information: donors who intend to give away all their money. Donors in this group did not lower their donation amount when norms were presented to them. This is good news for fundraisers intending to use social information as a charitable stimulant: our study shows that the effect of social information is restricted to a specific group of potential donors and that not everyone is affected.

Finally, our findings suggest that injunctive social information increases donations slightly above the suggested amount (five pounds) by decreasing the number of small donations, without decreasing the number of donations around the maximum. Social information, therefore, ensures that donors who would have donated lower amounts, donate higher amounts (in other words, it has a positive effect), without decreasing the number of high amounts (which would imply a negative effect). Hence, we further add to the literature by describing how social information works: the negative effect of social information (increasing the number of low donations) is smaller than the positive effect (increasing the effect of high donations).

\subsection{Limitations}

Whereas a field experiment in which participants make decisions about donating money they earned earlier is arguably the ideal setting for answering our research question, we considered an online experiment the next best thing.

A limitation of using windfall money to study giving behavior is that participants are more generous with windfall money than with earned money (Li et al. 2019). Therefore, we implemented pay-for-performance; participants had to earn the endowment by successfully completing the vocabulary test as an earned endowment is more likely to be considered as part of the participants' wealth than money that has simply been given (in other words, windfall gain) (Carlsson et al. 2013). We opted to pay only some participants because recent findings also support designs that pay only a few participants rather than all participants (Charness et al. 2016; Clot et al. 2018).

The data presented here do not allow conclusions regarding whether social information increases donors' total giving or whether it leads to substitution, i.e. one donation coming at the cost of another donation, and thus, the total amount given to charities remaining the same. We encourage future researchers to examine possible substitution effects as the result of social information. 


\section{Implications for practitioners}

Social information did not increase the number of donors (in other words, the conversion rate) in a significant manner, but it did increase the donation amount and donors' mood, although this effect did depend on the type of norm mentioned. The effect, however, is small. Mentioning injunctive social information was most effective in increasing both the donation amount (10\%) and donors' mood (10\%), but mentioning both injunctive and the descriptive social information at the same time led to the highest overall collected amount, mostly by increasing the decision to donate.

While the effect of social information on the donation amount is small, a clear advantage of social information is that it is easy to implement and that it is virtually costless. All that is needed is information on the average donation amount. In addition, our study shows that social information is a low-risk intervention. Social information affects the donation behavior by having a positive effect on the donation amount, without decreasing the number of donors. More specifically, it decreased the number of low donations (£1 - £5) without decreasing the number of high donations (£10). Next to this, social information increases rather than decreases people's mood. Based on our results, we advise practitioners to mention injunctive social information while attempting to affect donations.

Supplementary Information The online version contains supplementary material available at https://doi.org/ 10.1007/s12208-020-00270-3.

Funding This study was funded by a NWO grant (number 314-99-105).

Data availability Data, material and supplementary information can be found at https://osf.io/jqvaw/

\section{Compliance with ethical standards}

Conflict of interest Not applicable.

Code availability Not applicable.

Open Access This article is licensed under a Creative Commons Attribution 4.0 International License, which permits use, sharing, adaptation, distribution and reproduction in any medium or format, as long as you give appropriate credit to the original author(s) and the source, provide a link to the Creative Commons licence, and indicate if changes were made. The images or other third party material in this article are included in the article's Creative Commons licence, unless indicated otherwise in a credit line to the material. If material is not included in the article's Creative Commons licence and your intended use is not permitted by statutory regulation or exceeds the permitted use, you will need to obtain permission directly from the copyright holder. To view a copy of this licence, visit http://creativecommons.org/licenses/by/4.0/.

\section{References}

Alpizar, F., Carlsson, F., \& Johansson-Stenman, O. (2008). Does context matter more for hypothetical than for actual contributions? Evidence from a natural field experiment. Experimental Economics, 11, 299-324. 
Andreoni, J., Rao, J. M., \& Trachtman, H. (2017). Avoiding the ask: a field experiment on altruism, empathy, and charitable giving. Journal of Political Economy, 125(3), 625-653.

Banerjee, A. V., \& Besley, T. (1990). Peer group externalities and learning incentives: A theory of nerd behavior. Department of Economics/Woodrow Wilson School of Public and International Affairs, Princeton University.

Baumeister, R. F. (1998). The self. In D. T. Gilbert, S. T. Fiske, \& G. Lindzey (Eds.), The handbook of social psychology (pp. 680-740). New York: McGraw-Hill.

Bekkers, R. (2012). Limits of social influence on giving: Who is affected when and why? Presented at the Royal Over-seas League, London, Chicago, February 24, 2012, 1-49.

Bekkers, R. (2015). When and why matches are more effective subsidies than rebates. In C. Deck, E. Fatas, \& T. Rosenblat (Eds.), Research in experimental economics volume 18: Replication in economic experiments (pp. 183-211). Emerald Group Publishing.

Bekkers, R. \& van Teunenbroek, C. (2020). Generatieverschillen in geefgedrag In Bekkers, R., Schuyt, T. N. M., \& Gouwenberg, B. M. (Ed.), in Geven in Nederland 2020: Huishoudens, nalatenschappen, fondsen, bedrijven, goede doelenloterijen en vrijwilligers. Lenthe Publishers.

Bekkers, R., \& Wiepking, P. (2011). A literature review of empirical studies of philanthropy: eight mechanisms that drive charitable giving. Voluntary Sector Quarterly, 40(5), 924-973.

Bem, D. J. (1972). Self-perception theory. In L. Berkowitz (Ed.), Advances in experimental social psychology (Vol. 6, pp. 1-62). New York: Academic Press.

Bernheim, B. D. (1994). A theory of conformity. Journal of Political Economy, 102(5), 841-877.

Bicchieri, C., \& Xiao, E. (2009). Do the right thing: but only if others do so. Journal of Behavioral Decision Making, 22(2), 191-208.

Bikhchandani, S., Hirshleifer, D., \& Welch, I. (1992). A theory of fads, fashion, custom, and cultural change as informational cascades. Journal of Political Economy, 100(5), 992-1026.

Blake, R. R., Rosenbaum, M., \& Duryea, R. A. (1955). Gift-giving as a function of group standards. Human Relations, 8(1), 61-73.

Bøg, M., Harmgart, H., Huck, S., \& Jeffers, A. M. (2012). Fundraising on the internet. Kyklos, 65(1), 18-30.

Brehm, J., \& Brehm, S. (1981). Psychological reactance: A theory of freedom and control. New York: Academic Press.

Brewer, M. B., \& Roccas, S. (2001). Individual values, social identity, and optimal distinctiveness. In C. Sedikides \& M. B. Brewer (Eds.), Individual, self, relational self, collective self (pp. 219-237). Philadelphia: Psychology Press.

Carlsson, F., He, H., \& Martinsson, P. (2013). Easy come, easy go. Experimental Economics, 16(2), 190-207.

Catt, V., \& Benson, P. L. (1977). Effect of verbal modeling on contributions to charity. Journal of Applied Psychology, 62(1), 81-85.

Charness, G., Gneezy, U., \& Halladay, B. (2016). Experimental methods: pay one or pay all. Journal of Economic Behavior \& Organization, 131, 141-150.

Cialdini, R. B., Kallgren, C. A., \& Reno, R. R. (1991). A focus theory of normative conduct: recycling the concept of norms to reduce littering in public places. Journal of Personality and Social Psychology, 58(6), 1015-1026.

Clot, S., Grolleau, G., \& Ibanez, L. (2018). Shall we pay all? An experimental test of random incentivized systems. Journal of Behavioral and Experimental Economics, 73, 93-98.

Conlisk, J. (1980). Costly optimizers versus cheap imitators. Journal of Economic Behavior \& Organization, 1(3), 275-293.

Croson, R., \& Shang, J. (2008). The impact of downward social information on contribution decisions. Experimental Economics, 11(3), 221-233.

Croson, R., Handy, F., \& Shang, J. (2009). Keeping up with the Joneses: the relationship of perceived descriptive social norms, social informatio, and charitable giving. Nonprofit Management and Leadership, 19(4), 467-489.

Croson, R., \& Shang, J. (2013). Limits of the effect of social information on the voluntary provision of public goods: Evidence from field experiments. Economic Inquiry, 51(1), 473-477.

DellaVigna, S., List, J. A., \& Malmendier, U. (2012). Testing for altruism and social pressure in charitable giving. The Quarterly Journal of Economics, 127(1), 1-56.

Dunn, E. W., Aknin, L. B., \& Norton, M. I. (2014). Prosocial spending and happiness: using money to benefit others pays off. Current Directions in Psychological Science, 23(1), 41-47.

Dunn, E. W., Whillans, A. V., Norton, M. I., \& Aknin, L. B. (2020). Prosocial spending and buying time: Money as a tool for increasing subjective well-being. In Advances in experimental social psychology (Vol. 61, pp. 67-126). Academic Press. 
Edwards, J. T., \& List, J. A. (2013). Toward an understanding of why suggestions work in charitable fundraising: Theory and evidence from a natural field experiment (No. 4532).

Engel, C. (2011). Dictator games: a meta study. Experimental Economics, 14(4), 583-610.

Goeschl, T., Kettner, S., Lohse, J., \& Schwieren, C. (2018). From social information to social norms: evidence from two experiments on donation behaviour. Games, 9(4), 91.

Hagmann, K. R. S., Reese, G., Seewald, D., \& Loeschinger, D. C. (2015). Affixing the theory of normative conduct (to your mailbox): Injunctive and descriptive norms as predictors of anti-ads sticker use. Journal of Environmental Psychology, 44, 1-9.

Harbaugh, W. T., Mayr, U., \& Burghart, D. R. (2007). Neural responses to taxation and voluntary giving reveal motives for charitable donations. Science, 316, 1622-1625.

Hayes, A. F., \& Preacher, K. J. (2014). Statistical mediation analysis with a multicategorical independent variable. British Journal of Mathematical and Statistical Psychology, 67(3), 451-470.

Katz, M. L., \& Shapiro, C. (1986). Technology adoption in the presence of network externalities. Journal of Political Economy, 94(4), 822-841.

Kawamura, T., Ida, T., \& Ogawa, K. Simultaneous Effect of Monetary and Non-Monetary Interventions on Crowd-Funding Field Experimental Evidence: R\&D in New Sources of Energy (No. e-18-005).

Klinowski, D. (2015). Reluctant donors and their reactions to social information. Retrieved from http://spihub. org/site/resource_files/publications/spi_wp_120_jasper.pdf

Kubo, T., Shoji, Y., Tsuge, T., \& Kuriyama, K. (2018). Voluntary contributions to Hiking Trail maintenance: evidence from a field experiment in a National Park, Japan. Ecological Economics, 144, 124-128.

Li, H., Liang, J., Xu, H., \& Liu, Y. (2019). Does windfall money encourage charitable giving? An experimental study. Voluntas: International Journal of Voluntary and Nonprofit Organizations, 30(4), 841-848.

Lin, M., Lucas Jr., H. C., \& Shmueli, G. (2013). Too big to fail: large samples and the p-value problem. Information Systems Research, 24(4), 906-917.

Malhotra, N., Krosnick, J. A., \& Haertel, E. (2007). The psychometric properties of the GSS Wordsum vocabulary test. GSS Methodological Report, 11.

Meyer, A., \& Yang, G. (2016). How much versus who: which social norms information is more effective? Applied Economics, 48(5), 389-401.

Murphy, J. J., Batmunkh, N., Nilsson, B., \& Ray, S. (2015). The impact of social information on the voluntary provision of public goods: a replication study. Research in Experimental Economics, 18, 41-50.

O'Malley, M. N., \& Andrews, L. (1983). The effect of mood and incentives on helping: are there some things money can't buy? Motivation and Emotion, 7(2), 179-189.

Pool, G. J., Wood, W., \& Leck, K. (1998). The selfesteem motive in social influence: agreement with valued majorities and disagreement with derogated minorities. Journal of Personality and Social Psychology, 75, 967-975.

Raihani, N. J., \& Smith, S. (2015). Competitive helping in online giving. Current Biology, 25(9), 1183-1186.

Reingen, P. H. (1982). Test of a list procedure for inducing compliance with a request to donate money. Journal of Applied Psychology, 67(1), 110-118.

Reno, R. R., Cialdini, R. B., \& Kallgren, C. A. (1993). The transsituational influence of social norms. Journal of personality and social psychology, 64(1), 104.

Rivis, A., \& Sheeran, P. (2003). Descriptive norms as an additional predictor in the theory of planned behaviour: a meta-analysis. Current Psychology, 22(3), 218-233.

Sasaki, S. (2019). Majority size and conformity behavior in charitable giving: field evidence from a donationbased crowdfunding platform in Japan. Journal of Economic Psychology, 70, 36-51.

Schultz, P. W., Nolan, J. M., Cialdini, R. B., Goldstein, N. J., \& Griskevicius, V. (2018). The constructive, destructive, and reconstructive power of social norms: reprise. Perspectives on Psychological Science, 13(2), 249-254.

Shang, J., Reed, A., \& Croson, R. T. A. (2008). Identity congruency effects on donations. Journal of Marketing Research, 45(3), 351-361.

Shang, J., \& Croson, R. (2009). A field experiment in charitable contribution: the impact of social information on the voluntary provision of public goods. The Economic Journal, 119(540), 1422-1439.

Shang, J., Croson, R. T. A., \& Reed, A. (2012). "I" give, but "we" give more: The impact of identity and the mere social information effect on donation behavior. Journal of Marketing Research, (forthcoming).

Smith, S., Windmeijer, F., \& Wright, E. (2015). Peer effects in charitable giving: evidence from the (running) field. The Economic Journal, 125(585), 1053-1071.

Steinberg, R. (1987). Voluntary donations and public expenditures in a federalist system. The American Economic Review, 24-36. 
Thaler, R. H., \& Sunstein, C. R. (2008). Nudge: Improving decisions about health, wealth, and happiness. New Haven: Yale University Press.

Thöni, C., \& Volk, S. (2018). Conditional cooperation: review and refinement. Economics Letters, 171, 3740.

Van Teunenbroek, P. S. C. (2016). Social aspects and successfully funding a crowd-funding project: the impact of social information. Science, Engineering and Technology, International Journal of Social, Behavioral, Educational, Economic, Business and Industrial Engineering, 10(6), 1765-1776.

Van Teunenbroek, C., \& Bekkers, R. (2020). Follow the crowd: social information and crowdfunding donations in a large field experiment. Journal of Behavioral Public Administration, 3(1).

Van Teunenbroek, C. \& Bekkers, R. (2020a). Geven door huishoudens In Bekkers, R., Schuyt, T. N. M., \& Gouwenberg, B. M. (Ed.) Geven in Nederland 2020: Huishoudens, nalatenschappen, fondsen, bedrijven, goede doelenloterijen en vrijwilligers. Lenthe Publishers.

Van Teunenbroek, C., Bekkers, R., \& Beersma, B. (2020). Look to others before you leap: a systematic literature review of social information effects on donation amounts. Nonprofit and Voluntary Sector Quarterly, 49(1), 53-73.

Weinstein, N., \& Ryan, R. M. (2010). When helping helps: autonomous motivation for prosocial behavior and its influence on well-being for the helper and recipient. Journal of Personality and Social Psychology, 98(2), 222-244.

Whillans, A. V., Dunn, E. W., Smeets, P., Bekkers, R., \& Norton, M. I. (2017). Buying time promotes happiness. Proceedings of the National Academy of Sciences, 114(32), 8523-8527.

Registration: This article was pre-registered as OTHERS ARE DOING IT TOO under number 20805 and available through As Predicted at https://aspredicted.org/vz83y.pdf

\section{Affiliations}

\section{Claire van Teunenbroek ${ }^{1} \cdot$ René Bekkers $^{1} \cdot$ Bianca Beersma $^{2}$}

1 Department of Sociology, Vrije Universiteit Amsterdam, De Boelelaan 1081, 1081 HV Amsterdam, the Netherlands

2 Department of Organization Sciences, Vrije Universiteit Amsterdam, De Boelelaan 1081, 1081

HV Amsterdam, the Netherlands 